\title{
Book Review: Some Assembly Required: Decoding Four Billion Years of Life, From Ancient Fossils to DNA
}

\section{By Neil Shubin, Pantheon Books. 2020. ISBN: $9781101871331 . \$ 26.95$ (Print). Reviewed by Molly Selba, University of Florida}

In Some Assembly Required, Neil

SOME ASSEMBLY

REQUIRED

Decoding Four Billion Years of

Life, from Ancient Fossils to DNA

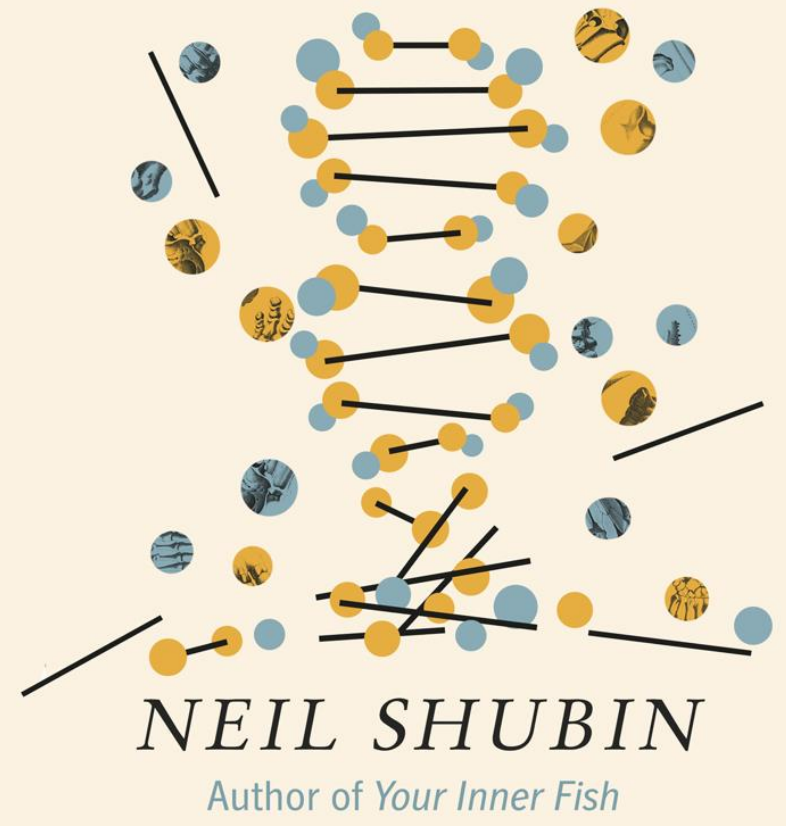

Shubin discusses major trends in evolution in the last four billion years of life on Earth through a collection of scientific discovery stories. He details the scientific breakthroughs that have helped us understand how new species evolve, demystifying the misconceptions surrounding heredity and natural selection. Throughout the book, Shubin paints in broad strokes the discoveries that inform our current understanding of evolution and natural selection. He discusses the speed at which evolution happens, ontogeny and changes in developmental timing, and the genes and their mutations that act as fodder for natural selection. Evolutionary change is examined on both a species level and at the level of the gene, and with each subsequent chapter, he builds upon the complexity of his argument and further develops the reader's understanding of the mechanics of evolution. Throughout the book, Neil Shubin effortlessly intertwines his own experiences

as a scientist with a wide range of research topics including morphology, cellular biology, paleontology, and genetics. Instead of presenting a neat and clean description of our current understanding of how evolutionary processes unfold, Shubin leads us through the successive discoveries that incrementally informed modern evolutionary theory. Simultaneously, Shubin debunks many misconceptions about the process of evolution that persist to this day, including the idea that every change in genes results in a change in anatomy. He complicates the notion, for example, that one sudden change can result in all the needed adaptations for a fish to live on land or a bird to experience flight. These types of morphological adaptations do not occur overnight, and instead are the result of a series of predictable pathways that lead to a variety of outcomes bound by physical and environmental constraints. 
Although the book covers many of the same topics that would be found in an introductory textbook on evolutionary biology, Shubin approaches these topics through the viewpoint of a scientific storyteller. He describes the elements of scientific discovery that often get excluded from our textbooks- the process of trial and error, mistakes, victories, collaborations, etc. The book provides readers with a background into the lives of some of the major players in the field of evolutionary biology while still tackling larger topics like phylogeny, ontogeny, and evolutionary change over time. Additionally, Shubin includes the accounts of many lesser-known female and minority scientists that made significant contributions to our understanding of the development of life on Earth. He addresses the fact that many of the more famous early scientists that are known for their accomplishments in evolutionary biology often had a fair amount of privilege: these scientists were typically European males with family money and access to an abundance of resources. Together, the inclusion of the names and backgrounds of the more modern scientists that often broke through barriers and shattered ceilings with the acknowledgment of this past privilege portray the field of science as one that is finally working towards diversity and inclusion.

As a scientist himself, Shubin describes many of the exciting elements of being involved in scientific research. He details exciting fieldwork such as expeditions to the south pole in search of emperor penguin eggs, late night breakthroughs in the lab, random and unexpected 'aha' moments, and collaborations with knowledgeable yet eccentric academics. He discusses how rivalries form between academics and how collaboration can help overcome a variety of roadblocks. Shubin portrays the field of science as an ongoing collaborative effort with many subsequent revisions and iterations. The book is as much about the scientists themselves as it is about their discoveries. For students that may be considering a career in the sciences, these aspects may encourage them to take the leap and consider pursuing scientific research. Additionally, for first generation students or students without access to a mentor within academia, this book provides great insight into life as a research scientist and many of the realities that come along with that career choice (writing grants, attending annual field-specific meetings, etc.).

This book is valuable for both undergraduate and graduate students as well as advanced high schoolers. It could easily be incorporated in an introductory evolutionary biology course or read as a comprehensive review for graduate students studying evolutionary sciences. It would also be suitable for a more general lay audience. Although some of the concepts are a bit more advanced than what would be included in a typical high school or non-science college curriculum, Shubin spends time covering many concepts such as meiosis and mitosis to bring any out-of-field readers up to speed. This book would be a great supplemental read in a course on the history of morphology, evolutionary development, or could even be used during discussions on the nature of science. Moreover, the 'Further Reading and Notes' section at the end of the book provides a comprehensive list of additional resources that may be useful to both academics and causal readers alike. 